\title{
Achieving Good Glycemic Control Early After Onset of Diabetes: A Cost-Effectiveness Analysis in Patients with Type 1 Diabetes in Sweden
}

\author{
Johan Jendle • Åsa Ericsson • Barnaby Hunt • William J. Valentine • \\ Richard F. Pollock (D)
}

Received: October 23, 2017 / Published online: December 4, 2017

(C) The Author(s) 2017. This article is an open access publication

\begin{abstract}
Introduction: Sweden has amongst the highest incidence rates of type 1 diabetes (T1D) in Europe. The high incidence and chronic nature of T1D result in high prevalence and economic burden. Improving glycemic control reduces the incidence of microvascular complications, which in turn reduces medical costs. The present study aimed to quantify the reductions in cost and improvements in quality-adjusted life expectancy with varying reductions in HbA1c in the T1D population.

Methods: The IQVIA CORE Diabetes Model was used to simulate a typical Swedish population of patients with T1D experiencing HbA1c reductions from $0.1 \%$ to $0.8 \%$ (in $0.1 \%$ increments) from $7.9 \%$ at baseline. Analyses were conducted in simulated cohorts based on data from the Swedish National Diabetes Register (NDR) and
\end{abstract}

Enhanced content To view enhanced content for this article go to http://www.medengine.com/Redeem/ D7FCF0602C20A35C.

J. Jendle

School of Medical Sciences, Örebro University,

Örebro, Sweden

A. Ericsson

Novo Nordisk Scandinavia AB, Malmö, Sweden

B. Hunt · W. J. Valentine · R. F. Pollock ( $₫)$

Ossian Health Economics and Communications

$\mathrm{GmbH}$, Basel, Switzerland

e-mail:pollock@ossianconsulting.com in subgroups by sex, smoking status, and body mass index (BMI), with different sets of qualityof-life utilities included. Generalized least squares (GLS) models were used to test for significant differences between subgroups. Analyses were also performed to investigate the effect of the duration of HbA1c control. Analyses were run over 50 years and outcomes discounted at $3 \%$ per annum.

Results: In the reference case analysis, reducing HbA1c lowered the incidence of microvascular and macrovascular complications and improved quality-adjusted life expectancy. GLS models identified a significantly larger benefit of reducing HbA1c in women over men, but found no significant differences in the magnitude of quality of life improvements with decreasing HbA1c when segregating by smoking status or BMI.

Conclusions: Reducing HbA1c in a population with T1D would reduce the incidence of microvascular complications, improve life expectancy and quality of life. Larger quality-oflife benefits were observed in younger and female adult patients, but no notable differences were observed in the benefits of glycemic control in smokers versus non-smokers or in patients with low or high BMI.

Funding: Novo Nordisk Scandinavia $A B$, Malmö, Sweden. 
Keywords: Costs and cost analysis; Diabetes mellitus, type 1; Quality of life; Long-term complications; Sweden

\section{INTRODUCTION}

The Diabetes Incidence Study in Sweden (DISS) reported an annual incidence of type 1 diabetes of 21.4 per 100,000 in men and 17.1 per 100,000 in women aged 0-34 years with a cumulative incidence of $0.748 \%$ in men and $0.598 \%$ in women by age 35 [1]. Analyses of other Swedish registries including the Prescribed Drug Register (PDR) and National Diabetes Register (NDR) have, however, yielded much higher estimates of incidence than DISS, and Sweden has the second highest standardized incidence of type 1 diabetes of the 17 countries included in the EURODIAB Study, second only to Finland [2, 3]. The high incidence of type 1 diabetes combined with the chronic nature of the condition results in a high prevalence, and the comorbidities associated with high blood glucose in turn result in a high economic burden.

The Diabetes Control and Complications Trial (DCCT) in patients with type 1 diabetes demonstrated that improved glycemic control leads to improved long-term clinical outcomes [4]. Over an average of 6.5 years of follow-up, intensive glycemic control in the DCCT (with a median $\mathrm{HbA} 1 \mathrm{c}$ of $7 \%$ or $53 \mathrm{mmol} / \mathrm{mol}$ ) resulted in reductions in the incidence of retinopathy, neuropathy, and nephropathy relative to conventional glycemic control (with a median HbA1c of 9\%) [4]. The Epidemiology of Diabetes Interventions and Complications (EDIC) trial was an observational extension of the DCCT with the primary objective of investigating the effects of intensive glycemic control on macrovascular complications and more advanced stages of microvascular complications. After 20 years, $88 \%$ of the original cohort were still being followed, showing major beneficial effects of intensive glycemic control in terms of advanced complications [5], including retinopathy [6], glomerular filtration rate [7], erectile dysfunction [8], and atherosclerosis $[9,10]$. However, the improvements in both microvascular and macrovascular outcomes were accompanied by increased rates of hypoglycemia and increased insulin use, which are in turn associated with additional costs and reduced quality of life. Studies conducted specifically in Swedish populations have shown the same correlation: patients with type 1 diabetes duration of at least 50 years without a history of macrovascular disease were significantly younger and had significantly lower HbA1c levels, body mass index (BMI), and triglyceride levels than those with a history of macrovascular disease [11].

The primary objective of the present analysis was to use a published and validated model of type 1 diabetes to evaluate the effects of different improvements in glycemic control on clinical outcomes and costs in a simulated cohort of patients with type 1 diabetes in Sweden. Secondarily, a series of analyses were run to establish patient groups (age, sex, and BMI) in which improving glycemic control would result in the largest improvements in health-related quality of life. The relative contributions of different groups of complications to changes in quality of life were also explored.

\section{METHODS}

Version 9.0 of the IQVIA CORE Diabetes Model (CDM), a published, validated model of type 1 diabetes, was used to simulate clinical and economic outcomes up to a 50-year time horizon [12]. The CDM was used in type 1 diabetes mode and was configured to use cardiovascular risk models based on EDIC data, with no restrictions to HbA1c adjustments. In the reference case analysis, the simulated cohort was based primarily on data from the Swedish NDR (Table 1) [13]. History of diabetes complication incidence at baseline was based on a number of studies from the Swedish NDR $[14,15]$. The cohort size was set to 1000 patients and the CDM was configured to perform 1000 bootstrap iterations for each analysis. Since the present analysis was based exclusively on the outputs of a computer simulation model, no studies of human or animal subjects were performed by any of the authors as part of the current work. 
Table 1 Mean baseline characteristics of the simulated type 1 diabetes cohort as reported by Cederholm et al. [13] $(N=3661)$

\begin{tabular}{ll}
\hline Characteristic & Value \\
\hline Baseline age (years) & 44.6 \\
Baseline duration of diabetes (years) & 28.0 \\
Proportion male (\%) & 55.6 \\
HbAlc $[\%(\mathrm{mmol} / \mathrm{mol})]$ & $7.9(62.8)$ \\
SBP $(\mathrm{mmHg})$ & 130 \\
BMI $\left(\mathrm{kg} / \mathrm{m}^{2}\right)$ & 25.4 \\
Total cholesterol $[\mathrm{mg} / \mathrm{dL}(\mathrm{mmol} / \mathrm{L})]$ & $193.9(5.0)$ \\
HDL $[\mathrm{mg} / \mathrm{dL}(\mathrm{mmol} / \mathrm{L})]$ & $61.9(1.6)$ \\
Smokers $(\%)$ & 14.8 \\
\hline
\end{tabular}

Costs of diabetes complications were based on data from Gerdtham et al. and supplemented with data from Sveriges Kommuner och Landsting [16-28]. Complication costs were reported in 2015 Swedish kronor and future cost and quality-adjusted life expectancy outcomes were discounted at 3\% per annum in line with health economic guidance for Sweden [29]. No insulin costs were captured in the analyses to evaluate the magnitude of cost differences arising from differences in complication incidence alone. In the reference case, nine analyses were performed, starting with the baseline cohort and reducing $\mathrm{HbA} 1 \mathrm{c}$ by $0.1 \%$ in year 1 in each of the other eight analyses. After the initial reduction, HbA1c levels were held flat for the remainder of the analysis although sensitivity analyses were conducted around this assumption. Other risk factors supported by the CDM (including BMI, diastolic and systolic blood pressure, serum lipid concentrations, and estimated glomerular filtration rate) were left to progress on the basis of the CDM default progressions, but with no differences between the simulation arms.

Since lower plasma glucose levels are typically accompanied by an increased risk of hypoglycemia, rates of non-severe hypoglycemia were increased alongside the reduced
HbA1c. The association between HbA1c and non-severe hypoglycemia rates was based on a second-order polynomial fit to a curve published by Mullins et al. relating HbA1c to nonsevere hypoglycemia rates with insulin glargine [30]. The rate of hypoglycemia per 100 patient years was determined for each HbA1c concentration (in \%) using the following formula:

$$
\begin{aligned}
R_{\text {hypo }}= & 7927.4-1181.8 \cdot \mathrm{HbA} 1 \mathrm{c}+49.5 \\
& \cdot \text { HbA1c }^{2} .
\end{aligned}
$$

A series of subgroup analyses were performed, including analyses of exclusively male and female patients, smokers and nonsmokers, and patients with BMI of 20 and $30 \mathrm{~kg} /$ $\mathrm{m}^{2}$, all conducted over the full range of HbA1c reductions $\quad(0-0.8 \% ; \quad 0-8.8 \mathrm{mmol} / \mathrm{mol}) \quad$ to establish whether differential benefits of lower HbA1c were observed in specific patient groups. Analyses were also conducted in which HbA1c was held flat for 10 and 20 years rather than the full 50-year time horizon, returning to the baseline value of $7.9 \%(62.8 \mathrm{mmol} / \mathrm{mol})$ after each time period based on the Swedish NDR baseline. Finally, analyses were conducted to establish the magnitude of the contribution of different groups of complications on healthrelated quality of life over the range of $\mathrm{HbA1c}$ reductions. Quality of life utilities were grouped into cardiovascular (MI, stroke, and angina), ocular (retinopathy and macular edema), renal (microalbuminuria, gross proteinuria, and endstage renal disease covering hemodialysis, peritoneal dialysis, and renal transplant), and peripheral vascular disease (covering peripheral vascular disease, diabetic foot ulcer, and amputation).

The significance of differences between pairwise subgroup analyses (e.g., smoker and non-smoker) was assessed by first deriving linear models (using the $\mathrm{R} \mathrm{lm}$ function) from the nine incremental quality-adjusted life expectancy (QALE) values at each HbA1c decrement using incremental QALE as the response vector and $\mathrm{HbA} 1 \mathrm{c}$ decrement as the linear predictor of incremental QALE. A generalized least squares model was then created (using the R gls function) by appending the two datasets as the dependent variable, and using the (duplicated) 
original independent variable (HbA1c) and the interaction between a dummy variable $(0=$ non-smoker, $1=$ smoker $)$ and the independent variable as the explanatory variables (Code 1 ). The $p$ value (under a $t$ approximation) associated with the coefficient of the interaction term (between HbA1c and the dummy variable) was then used to establish the significance of the difference at the $p<0.05$ level (Table 2).

\section{RESULTS}

Running a representative Swedish type 1 diabetes population through the IQVIA CORE Diabetes Model with increasing treatment-associated HbA1c benefits showed a consistent reduction in the incidence of microvascular and macrovascular complications with decreasing HbA1c. The cumulative incidence of eye complications and renal complications (Fig. 1) reduced linearly with HbA1c. Over the full $0.8 \%$ $(8.8 \mathrm{mmol} / \mathrm{mol})$ reduction in $\mathrm{HbA} 1 \mathrm{c}$, the largest reduction in cumulative incidence was reported in proliferative diabetic retinopathy with a relative risk of 0.47 over the 50-year time horizon
(Table 3). Relative risk reductions were less pronounced for macrovascular complications (congestive heart failure, angina, stroke, and myocardial infarction) than for microvascular complications. While relative reductions in cumulative incidence were comparable across all macrovascular complications (11.3-14.6\%), the higher "reference" prevalence of myocardial infarction and angina (i.e., with no reduction in HbA1c) resulted in absolute risk reductions of $2.26 \%$ and $1.53 \%$ with a $0.8 \%(8.8 \mathrm{mmol} / \mathrm{mol})$ HbA1c reduction. This compared to more modest absolute reductions in congestive heart failure and stroke of $0.45 \%$ for both complications with a $0.8 \% \quad(8.8 \mathrm{mmol} / \mathrm{mol}) \quad \mathrm{HbA} 1 \mathrm{c}$ reduction (Fig. 2).

Quality of life improved linearly with decreasing HbA1c; in the baseline cohort (HbA1c of $7.9 \%$ or $62.8 \mathrm{mmol} / \mathrm{mol}$ ), qualityadjusted life expectancy was 12.21 quality-adjusted life years (QALYs) compared to 12.78 QALYs in the $-0.8 \%(8.8 \mathrm{mmol} / \mathrm{mol})$ cohort (HbA1c of $7.1 \%$ or $54.1 \mathrm{mmol} / \mathrm{mol}$ ), an improvement of 0.57 QALYs. Improvements in quality-adjusted life expectancy were much more pronounced in younger patients owing in part to the higher baseline life expectancy (Fig. 3). Relatedly, holding HbA1c constant for

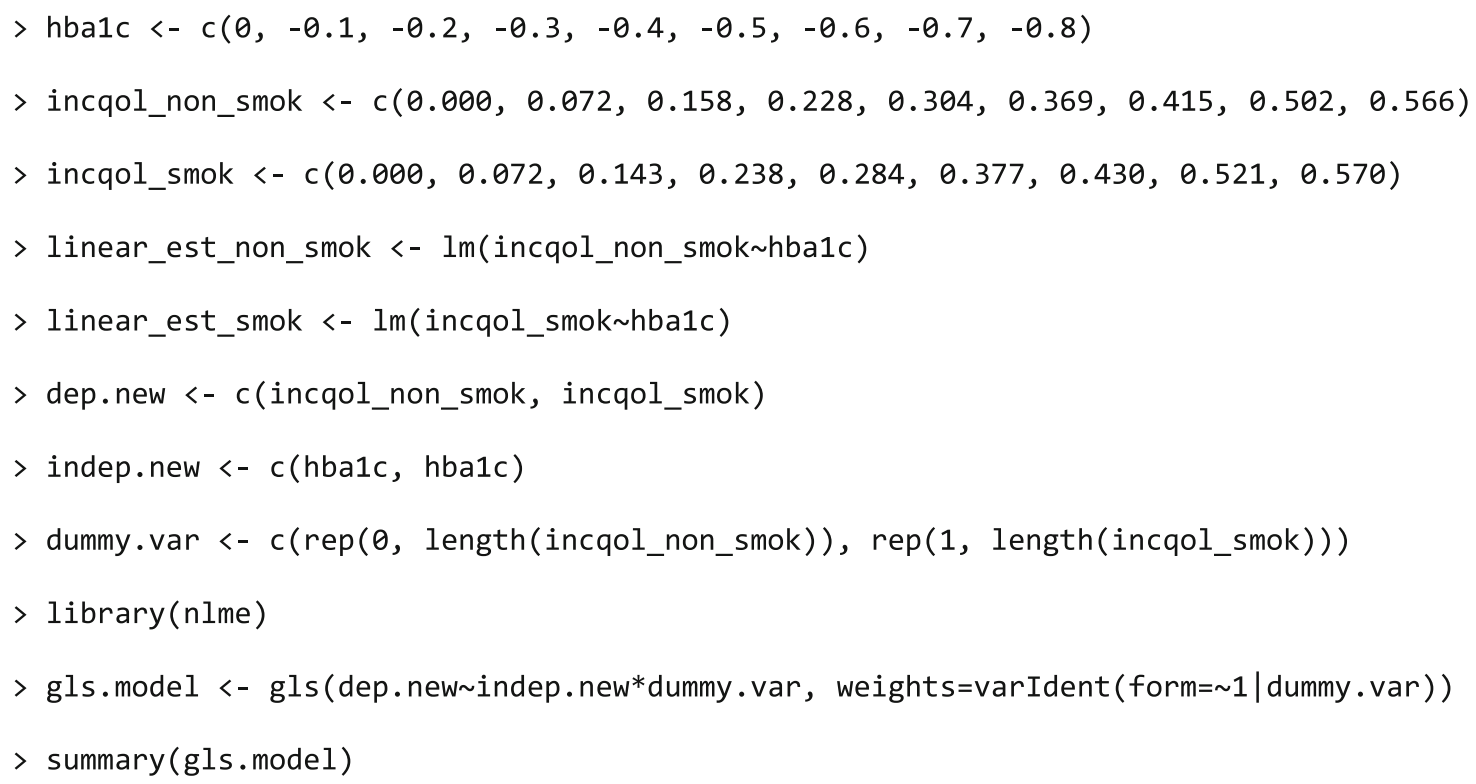

Code 1 Example R code for comparing linear models of incremental quality-adjusted life expectancy outcomes as a function of $\mathrm{HbAlc}$ in smokers versus non-smokers 
Table 2 Costs associated with diabetes complications and adverse events

\begin{tabular}{|c|c|c|}
\hline Complication or adverse event & $\begin{array}{l}\text { Cost } \\
\text { (SEK) }\end{array}$ & References \\
\hline $\begin{array}{l}\text { Myocardial infarction, year of } \\
\text { event }\end{array}$ & 101,463 & {$[16]$} \\
\hline $\begin{array}{l}\text { Myocardial infarction, } \\
\text { subsequent years }\end{array}$ & 2259 & [16] \\
\hline Angina, year of onset & 94,092 & [16] \\
\hline Angina, subsequent years & 5046 & [16] \\
\hline $\begin{array}{l}\text { Congestive heart failure, year of } \\
\text { onset }\end{array}$ & 71,445 & {$[16]$} \\
\hline $\begin{array}{l}\text { Congestive heart failure, } \\
\text { subsequent years }\end{array}$ & 7140 & {$[16]$} \\
\hline Stroke, year of event & 181,086 & {$[17]$} \\
\hline Stroke, subsequent years & 162,912 & {$[17]$} \\
\hline Stroke, death within 30 days & 100,741 & {$[16]$} \\
\hline Peripheral vascular disease, onset & 94,092 & {$[16]$} \\
\hline $\begin{array}{l}\text { Peripheral vascular disease, } \\
\text { subsequent years }\end{array}$ & 5046 & {$[16]$} \\
\hline Hemodialysis, onset & 499,768 & {$[19]$} \\
\hline Hemodialysis, subsequent years & 748,637 & {$[19]$} \\
\hline Peritoneal dialysis, onset & 499,768 & {$[19]$} \\
\hline $\begin{array}{l}\text { Peritoneal dialysis, subsequent } \\
\text { years }\end{array}$ & 748,637 & {$[19]$} \\
\hline Kidney transplant, first year & 470,839 & {$[20]$} \\
\hline $\begin{array}{l}\text { Kidney transplant, subsequent } \\
\text { years }\end{array}$ & 47,288 & {$[21]$} \\
\hline Severe hypoglycemia & 1462 & {$[22]$} \\
\hline Non-severe hypoglycemia & 67 & {$[23]$} \\
\hline Laser treatment & 61,769 & {$[24]$} \\
\hline Cataract operation & 34,427 & {$[24]$} \\
\hline $\begin{array}{l}\text { Cataract operation, subsequent } \\
\text { years }\end{array}$ & 916 & {$[25]$} \\
\hline Blindness, first year & 9248 & {$[26]$} \\
\hline Blindness, subsequent years & 3948 & {$[26]$} \\
\hline Neuropathy, year of onset & 42,840 & {$[27]$} \\
\hline
\end{tabular}

Table 2 continued

\begin{tabular}{lll}
\hline Complication or adverse event & $\begin{array}{l}\text { Cost } \\
\text { (SEK) }\end{array}$ & References \\
\hline Neuropathy, subsequent years & 42,840 & {$[28]$} \\
Amputation, procedure & 28,697 & {$[28]$} \\
Amputation, prosthesis & 21,714 & {$[18]$} \\
Gangrene treatment & 336,116 & {$[18]$} \\
Infected foot ulcer & 224,793 & {$[18]$} \\
Uninfected foot ulcer & 195,603 & {$[18]$} \\
\hline
\end{tabular}

10 years, 20 years, and the full model time horizon showed diminishing improvements in quality-adjusted life expectancy (Fig. 4). The first 10 years of control at an HbA1c level 7.1\% $(54.1 \mathrm{mmol} / \mathrm{mol})$ relative to $7.9 \%$ $(62.8 \mathrm{mmol} / \mathrm{mol})$ resulted in an improvement of 0.579 undiscounted QALYs, while the subsequent 10 years resulted in an additional gain of 0.432 QALYs and the final 30 years of control (to the time horizon of the analysis) improved life expectancy by an additional 0.239 QALYs.

As complication incidence was lower with lower $\mathrm{HbA} 1 \mathrm{c}$, costs of diabetes complications also decreased from SEK 761,000 in the reference cohort to SEK 669,000 in the $-0.8 \%$ cohort (Fig. 5), a reduction of SEK 92,000. Reducing HbA1c by $0.8 \%$ in a general diabetes population therefore increased quality of life by 0.57 QALYs, while reducing costs by SEK 92,000. At a willingness-to-pay (WTP) threshold of SEK 500,000 per QALY, this corresponds to a net monetary benefit (NMB) of SEK 377,000 over a 50-year time horizon (calculated as the product of the incremental quality-adjusted life expectancy and the WTP threshold summed with the incremental cost) [31]. Since the analysis excluded treatment costs, an estimate of the maximum annual cost-effective treatment cost for lowering $\mathrm{HbA} 1 \mathrm{c}$ by $0.8 \%$ can be calculated. Factoring in the annual discount rate of $3 \%$ and survival curves in patients with reduced HbA1c, an NMB of SEK 377,000 over 50 years would correspond to an additional SEK 19,575 per annum (in present-day values) available for a 


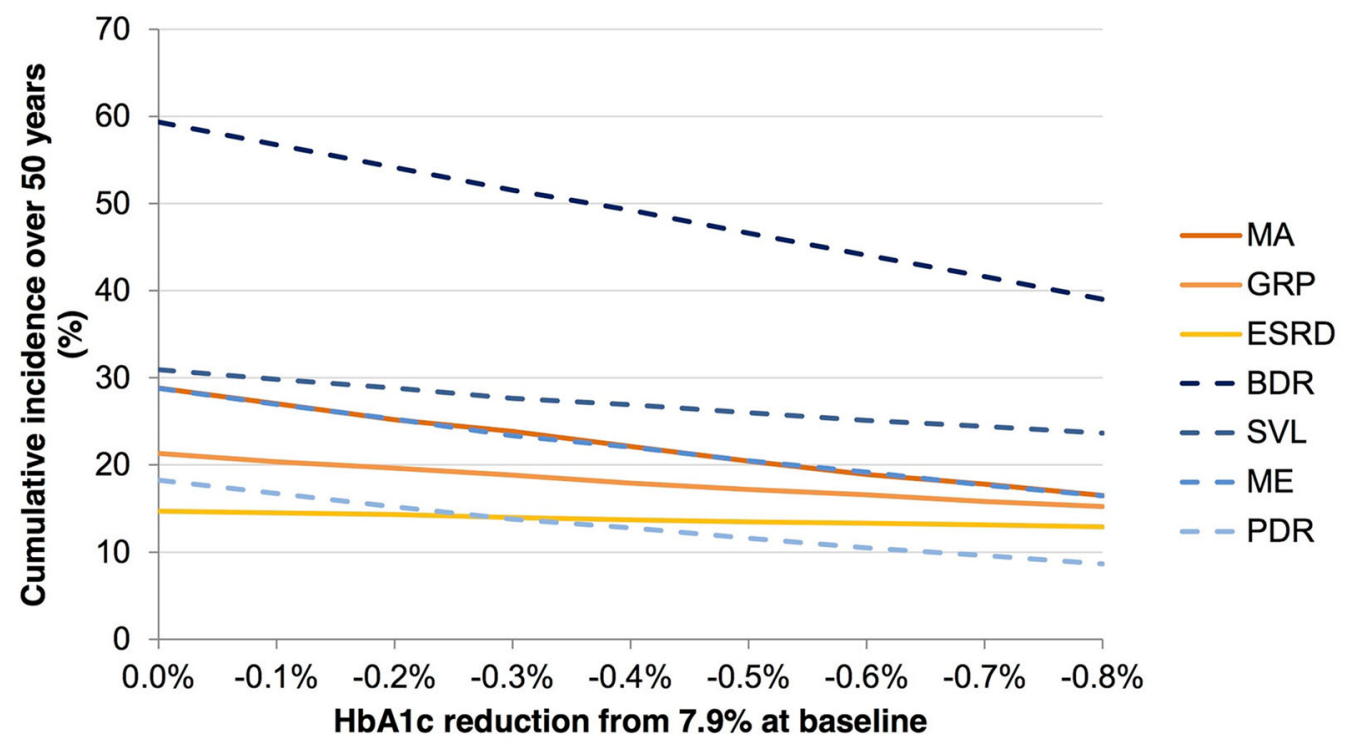

Fig. 1 Cumulative incidence of renal and eye complications over 50 years. Dashed lines show the cumulative incidence of ocular complications, while solid lines show the cumulative incidence of renal complications. $B D R$

diabetes treatment that would reduce $\mathrm{HbA1c}$ by $0.8 \%(8.8 \mathrm{mmol} / \mathrm{mol})$.

\section{Subgroup Analyses}

All subgroup analyses showed improvements in life expectancy and quality-adjusted life expectancy with reduced HbA1c. On the basis of the generalized least squares model approach, neither the smoking nor BMI subgroup analyses resulted in significant differences in the improvements in QALE between groups. In the models of smoking versus non-smoking, the interaction term coefficient was -0.0218 $(p=0.30)$, whereas in the models of low versus high BMI, the interaction term coefficient was $-0.013(p=0.5781)$. There was, however, a significant difference between men and women with an interaction term of $0.050(p=0.019)$. The linear models of the relationship between HbA1c reduction and QALE improvement in men and women both fit the data well, with $R^{2}>0.99$ and a residual standard error of 0.01 over seven degrees of freedom in both cases. The models showed a greater association with
Background diabetic retinopathy, ESRD end-stage renal disease, GRP gross proteinuria, $M A$ microalbuminuria, $M E$ macular edema, $P D R$ proliferative diabetic retinopathy, $S V L$ severe vision loss

reducing HbA1c and QALE in women over men, with gradient coefficients of -0.738 and -0.688 in women and men, respectively, corresponding to 0.0738 and 0.0688 QALY improvements in QALE in women and men for each $0.1 \%$ reduction in HbA1c over the 50 -year duration of the analysis, respectively.

\section{DISCUSSION}

Improving glycemic control was projected to reduce complication incidence and the associated costs while improving life expectancy and quality-adjusted life expectancy in patients with type 1 diabetes. Modeled improvements in microvascular complication incidence were more pronounced than those in macrovascular complications, but there was no increase in the projected incidence of any modeled complication with reduced $\mathrm{HbA1c}$. Analyses in which the baseline cohort was stratified by age and in which the HbA1c benefit was maintained over different time periods showed that early glycemic control in younger patients is most beneficial in terms of its overall effect on quality- 
Table 3 Cumulative incidence and relative risk of complications over 50 years with a $0.8 \%$ reduction in $\mathrm{HbAlc}$ in patients with type 1 diabetes

\begin{tabular}{|c|c|c|c|}
\hline & $\begin{array}{l}\text { Cumulative } \\
\text { incidence } \\
\text { with } \\
\text { HbA1c } \\
7.9 \%\end{array}$ & $\begin{array}{l}\text { Cumulative } \\
\text { incidence } \\
\text { with } \\
\text { HbA1c } \\
7.1 \%\end{array}$ & $\begin{array}{l}\text { Relative } \\
\text { risk }\end{array}$ \\
\hline $\begin{array}{l}\text { Background } \\
\text { diabetic } \\
\text { retinopathy }\end{array}$ & 59.4 & 39.0 & 0.66 \\
\hline $\begin{array}{l}\text { Proliferative } \\
\text { diabetic } \\
\text { retinopathy }\end{array}$ & 18.3 & 8.6 & 0.47 \\
\hline Macular edema & 28.8 & 16.5 & 0.57 \\
\hline Severe vision loss & 30.9 & 23.7 & 0.76 \\
\hline Microalbuminuria & 28.8 & 16.5 & 0.57 \\
\hline Gross proteinuria & 21.3 & 15.2 & 0.71 \\
\hline $\begin{array}{l}\text { End-stage renal } \\
\text { disease }\end{array}$ & 14.7 & 12.9 & 0.88 \\
\hline Ulcer & 35.6 & 26.6 & 0.75 \\
\hline $\begin{array}{l}\text { Amputation after } \\
\text { ulcer }\end{array}$ & 12.7 & 9.4 & 0.74 \\
\hline Neuropathy & 48.3 & 35.1 & 0.73 \\
\hline $\begin{array}{l}\text { Congestive heart } \\
\text { failure }\end{array}$ & 3.2 & 2.7 & 0.86 \\
\hline Angina & 13.6 & 12.0 & 0.89 \\
\hline Stroke & 3.1 & 2.6 & 0.85 \\
\hline $\begin{array}{l}\text { Myocardial } \\
\text { infarction }\end{array}$ & 17.1 & 14.9 & 0.86 \\
\hline
\end{tabular}

adjusted life expectancy. The diminishing effect of longer periods of control was particularly notable, with the first 10 years of control at an $\mathrm{HbA} 1 \mathrm{c}$ of $7.1 \%(54.1 \mathrm{mmol} / \mathrm{mol})$ improving quality-adjusted life expectancy by 0.297 QALYs compared to the final 30 years of control, which improved life expectancy by 0.083 QALYs. The cost analysis showed that SEK 19,575 per annum would be a justifiable cost of a diabetes treatment that could reduce $\mathrm{HbA1c}$ from $7.9 \%$ to $7.1 \%$ and maintain control over time.

Reductions in complication incidence varied across the modeled complications, with a notable difference in the relative reductions of microvascular and macrovascular complication incidence. Specifically, reduced HbA1c was seen to have a marked effect on microvascular complications, while much smaller changes in the risk of angina, stroke, myocardial infarction, and congestive heart failure. The risk reductions were more modest than those reported in the DCCT, which showed a $42 \%$ (95\% CI 9-63\%, $p=0.02)$ reduction in the risk of any cardiovascular disease event with intensive versus conventional treatment over an average of 6.5 years of follow-up [32]. Similarly, the risk of nonfatal myocardial infarction, stroke, or death from cardiovascular disease in the DCCT was reduced by $57 \%$ (95\% CI $12-79 \%, p=0.02)$ with intensive versus conventional glycemic control [32]. There could be many factors that drive the discrepancy, most notably that much larger reductions in HbA1c were observed in the DCCT intensive treatment group than were modeled in the present study. Over the 6.5 years of follow-up in the DCCT, HbA1c decreased from $9.1 \%(76.0 \mathrm{mmol} / \mathrm{mol})$ at baseline to $7.4 \%$ $(57.4 \mathrm{mmol} / \mathrm{mol})$ at end-of-study, a reduction of $1.7 \%(18.6 \mathrm{mmol} / \mathrm{mol})$ compared to the $0.8 \%$ $(8.8 \mathrm{mmol} / \mathrm{mol})$ modeled in the present study.

The finding of a significant difference between QALE outcomes with improved glycemic control in men versus women may have been driven by differences in mortality risks in male and female patients with type 1 diabetes in EDIC, which was the source of the data driving the cardiovascular risk equations. The EDIC study reported a higher standardized mortality ratio (SMR) in women (1.19) than men (1.04) relative to a baseline of the US general population in 2013 [33]. While the relative mortality ratio of 0.87 in EDIC was not significant $(p=0.464)$, the difference was not uniform across the population; models adjusting for time-dependent HbA1c values showed a significant interaction between sex and HbA1c $(p=0.016)$, in which the relative mortality among women relative to men increased with increasing HbA1c. Similarly, a recent meta- 


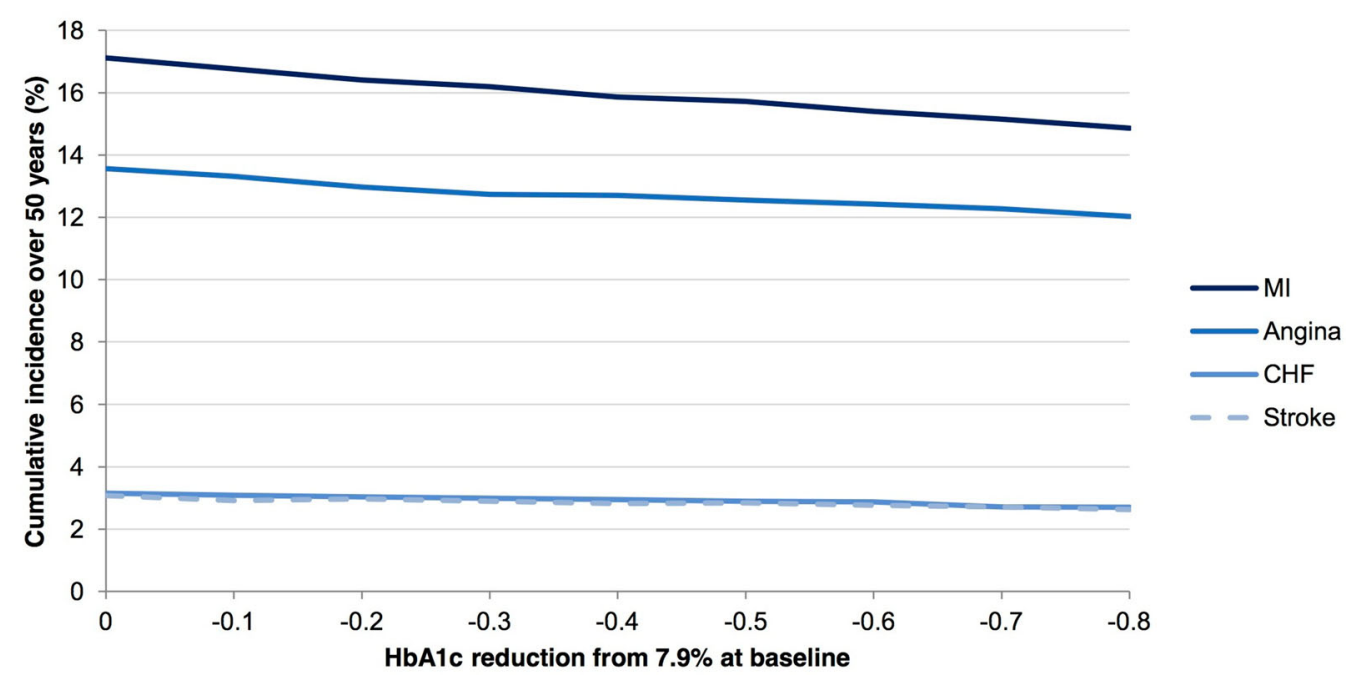

Fig. 2 Cumulative incidence of macrovascular complications over 50 years. $C H F$ congestive heart failure, $M I$ myocardial infarction

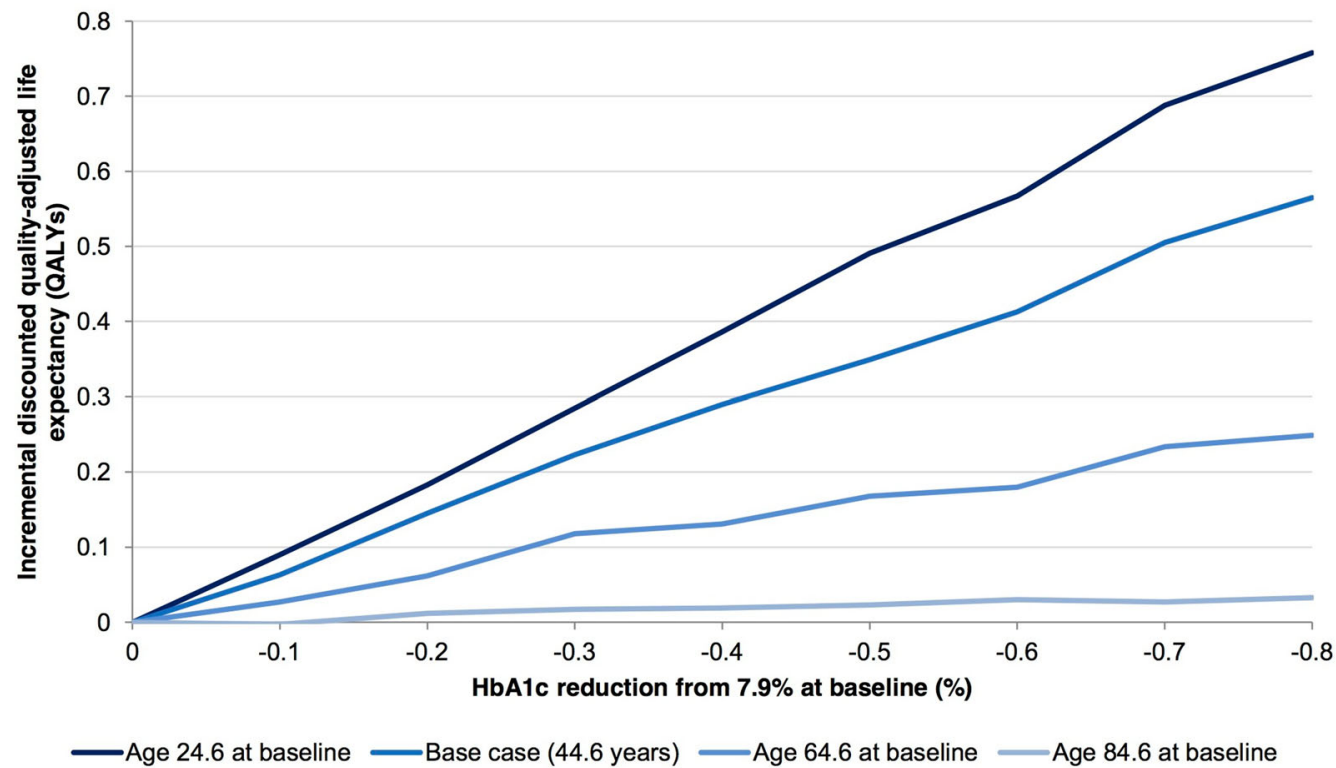

Fig. 3 Improvements in quality-adjusted life expectancy with decreasing HbAlc from $7.9 \%$ to $7.1 \%$ by baseline age

analysis of 197,396 individuals and 14,682 deaths showed a significant relative SMR (for all-cause mortality) of 1.37 in women relative to men $(p<0.0001)$ [34]. The meta-analysis authors noted that rather than the SMRs being simply an artifact of higher background mortality in men in the overall population, there is growing evidence to suggest a greater adverse effect of hyperglycemia and diabetes on vascular risk in women than men $[33,35,36]$. While these findings need not drive changes in health policy, the ability of existing models to capture these differences is useful from the perspective of healthcare decision-makers.

There are a number of limitations to the present study that should be acknowledged, the primary limitation being that all projections were based solely on a computer simulation 


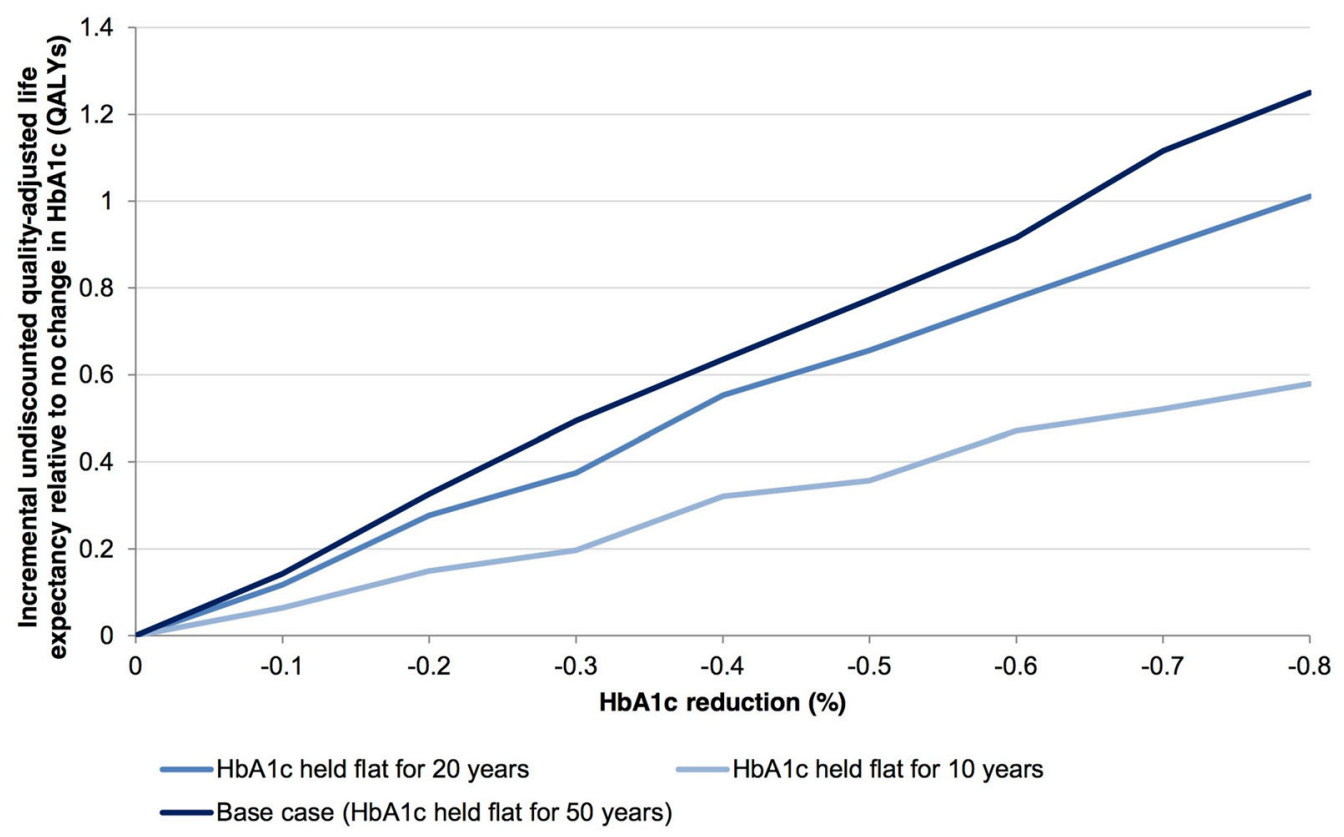

Fig. 4 Changes in quality-adjusted life expectancy with decreasing HbAlc relative to no change in $\mathrm{HbAlc}$ from baseline

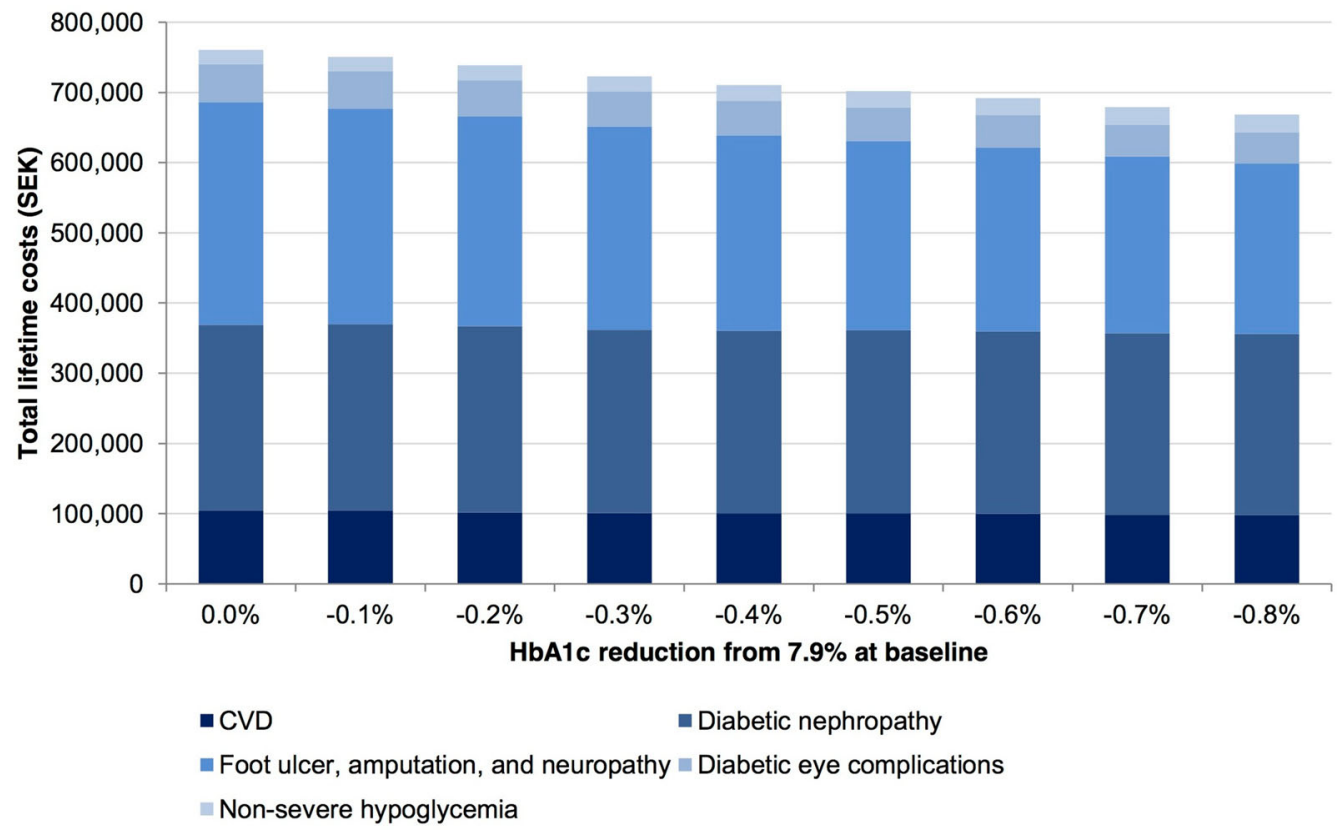

Fig. 5 Costs of adverse events and long-term diabetes complications with decreasing HbAlc

model of type 1 diabetes. The long-term nature of the projections necessitates the use of simulation techniques as no trials have been conducted with a sufficiently long follow-up period to cover patient lifetimes. The CDM was chosen as it represents a published and validated model and has recently been updated to include risk equations based on the long-term follow-up 
data from EDIC, therefore representing one of the best available options for modeling complication incidence and evaluating health economic outcomes in type 1 diabetes [37]. A second key limitation was the use of complication cost data derived predominantly from populations of patients with type 2 diabetes (e.g., the Gerdtham et al. study). Complication costs specific to patients with type 1 diabetes in Sweden could not be identified and we opted to prefer geographical specificity over diabetes type specificity for the present analysis. While cost estimates for complications experienced by patients with type 1 versus type 2 diabetes would almost certainly differ, the same cost estimates were used in the reference case $(7.9 \%$ with no reduction) and each $0.1 \%$ HbA1c decrement analysis, thereby partially mitigating the effect on the incremental cost projections and entirely mitigating the possibility of different complication unit costs affecting the directionality of the findings presented.

The rationale for modeling $\mathrm{HbA} 1 \mathrm{c}$ reductions from $0.1 \%$ up to $0.8 \%$ stems from a conservative interpretation of the reductions achievable by using existing diabetes medications or interventions. For instance, American Diabetes Association guidelines note that patients with type 1 diabetes switching from self-monitoring of blood glucose to continuous glucose monitoring could expect to see an $\mathrm{HbA} 1 \mathrm{c}$ reduction of $0.5 \%$ [38]. In the National Institute for Health and Care Excellence (NICE) review of continuous subcutaneous insulin infusion (CSII) versus multiple daily analogue insulin injections reported statistically significant reductions in $\mathrm{HbA} 1 \mathrm{c}$ of between $0.2 \%$ and $1.4 \%$ after initiation of CSII therapy [39]. The range also covers the typical magnitude of HbA1c reductions observed in randomized controlled trials of insulins prior to the widespread adoption of treat-to-target trials. For example, in adult patients with type 1 diabetes previously treated with a basal-bolus regimen, switching to insulin detemir resulted in HbA1c reductions of $0.43-0.49 \%$ [40]. Similarly, the PREDICTIVE study showed HbA1c reductions of between $0.4 \%$ and $0.6 \%$ with the use of insulin detemir in place of NPH insulin or insulin glargine as part of a basal-bolus regimen [41]. The magnitude of changes modeled in the present study could therefore be achieved through changes to insulin regimens or blood glucose monitoring practices costing up to SEK 19,575 per annum.

\section{CONCLUSIONS}

The present study illustrates the importance of early improved glycemic control and, using a monetary benefit analysis, provides an estimate of the budget available to spend on insulin in order to obtain a lower HbA1c in the average patient with type 1 diabetes in Sweden.

\section{ACKNOWLEDGEMENTS}

The authors are grateful to Novo Nordisk Scandinavia $\mathrm{AB}$, Malmö, Sweden for providing financial support for the present analysis, covering the data collection, modeling and statistical analyses, manuscript preparation and journal article processing fees. All authors had full access to all of the data in this study and take complete responsibility for the integrity of the data and accuracy of the data analysis. All named authors meet the International Committee of Medical Journal Editors (ICMJE) criteria for authorship for this manuscript, take responsibility for the integrity of the work as a whole, and have given final approval for the version to be published.

Disclosures. Åsa Ericsson is a full-time employee of Novo Nordisk Scandinavia AB. Barnaby Hunt is a full-time employee of Ossian Health Economics and Communications $\mathrm{GmbH}$, Richard Pollock is a full-time employee of Ossian Health Economics and Communications $\mathrm{GmbH}$, and William Valentine is a fulltime employee of Ossian Health Economics and Communications $\mathrm{GmbH}$, which received consultancy fees to perform the cost-effectiveness analysis and prepare the manuscript. Johan Jendle is Professor of Medical Science at Örebro University and Head at the Endocrine and Diabetes Centre at Karlstad Hospital, and has contributed to advisory boards for AstraZeneca, 
Boehringer Ingelheim, Eli Lilly, Medtronic, Novo Nordisk, Roche Diagnostics, and Sanofi in 2017, as well as chairing meetings/lectures for AstraZeneca, Boehringer Ingelheim, Eli Lilly, Nordic Infucare, MSD, Novo Nordisk, Pfizer, and Sanofi.

Compliance with Ethics Guidelines. Since the present analysis was based exclusively on the outputs of a computer simulation model, no studies of human or animal subjects were performed by any of the authors as part of the current work.

Open Access. This article is distributed under the terms of the Creative Commons Attribution-NonCommercial 4.0 International License (http://creativecommons.org/licenses/ by-nc/4.0/), which permits any noncommercial use, distribution, and reproduction in any medium, provided you give appropriate credit to the original author(s) and the source, provide a link to the Creative Commons license, and indicate if changes were made.

\section{REFERENCES}

1. Pundziute-Lyckå A, Dahlquist G, Nyström L, Swedish Childhood Diabetes Study Group, et al. The incidence of type I diabetes has not increased but shifted to a younger age at diagnosis in the 0-34 years group in Sweden 1983-1998. Diabetologia. 2002;45(6):783-91.

2. Rawshani A, Landin-Olsson M, Svensson AM, et al. The incidence of diabetes among 0-34 year olds in Sweden: new data and better methods. Diabetologia. 2014;57(7):1375-81.

3. Patterson CC, Dahlquist GG, Gyürüs E, Green A, Soltész G, EURODIAB Study Group. Incidence trends for childhood type 1 diabetes in Europe during 1989-2003 and predicted new cases 2005-20: a multicentre prospective registration study. Lancet. 2009;373(9680):2027-33.

4. The Diabetes Control and Complications Trial Research Group. The relationship of glycemic exposure (HbA1c) to the risk of development and progression of retinopathy in the diabetes control and complications trial. Diabetes. 1995;44(8):968-83.
5. Nathan DM, Zinman B, Cleary PA, Diabetes Control and Complications Trial/Epidemiology of Diabetes Interventions and Complications (DCCT/EDIC) Research Group, et al. Modern-day clinical course of type 1 diabetes mellitus after 30 years' duration: the Diabetes Control and Complications Trial/Epidemiology of Diabetes Interventions and Complications and Pittsburgh Epidemiology of Diabetes Complications Experience (1983-2005). Arch Intern Med. 2009;169:1307-16.

6. Aiello LP, Sun W, Das A, DCCT/EDIC Research Group, et al. Intensive diabetes therapy and ocular surgery in type 1 diabetes. $\mathrm{N}$ Engl J Med. 2015;372(18):1722-33.

7. de Boer IH, Sun W, Cleary PA, DCCT/EDIC Research Group, et al. Intensive diabetes therapy and glomerular filtration rate in type 1 diabetes. N Engl J Med. 2011;365:2366-76.

8. Wessells H, Penson DF, Cleary P, DCCT/EDIC Research Group, et al. Effect of intensive glycemic therapy on erectile function in men with type 1 diabetes. J Urol. 2011;185:1828-36.

9. Nathan DM, Lachin J, Cleary P, Diabetes Control and Complications Trial, Epidemiology of Diabetes Interventions and Complications Research Group, et al. Intensive diabetes therapy and carotid intimamedia thickness in type 1 diabetes mellitus. N Engl J Med. 2003;348:2294-303.

10. Cleary PA, Orchard TJ, Genuth S, DCCT/EDIC Research Group, et al. The effect of intensive glycemic treatment on coronary artery calcification in type 1 diabetic participants of the Diabetes Control and Complications Trial/Epidemiology of Diabetes Interventions and Complications (DCCT/EDIC) Study. Diabetes. 2006;55:3556-65.

11. Eryd AS, Svensson AM, Franzén S, Eliasson B, Nilsson PM, Gudbjörnsdottir S. Risk of future microvascular and macrovascular disease in people with type 1 diabetes of very long duration: a national study with 10-year follow-up. Diabet Med. 2016. https://doi.org/10.1111/dme.13266.

12. Palmer AJ, Roze S, Valentine WJ, et al. The CORE Diabetes Model: projecting long-term clinical outcomes, costs and cost-effectiveness of interventions in diabetes mellitus (types 1 and 2) to support clinical and reimbursement decision-making. Curr Med Res Opin. 2004;20(Suppl 1):S5-26.

13. Cederholm J, Eeg-Olofsson K, Eliasson B, Zethelius B, Gudbjörnsdottir S. A new model for 5-year risk of cardiovascular disease in type 1 diabetes; from the Swedish National Diabetes Register (NDR). Diabet Med. 2011;28(10):1213-20. 
14. Lind M, Bounias I, Olsson M, Gudbjörnsdottir S, Svensson AM, Rosengren A. Glycaemic control and incidence of heart failure in 20,985 patients with type 1 diabetes: an observational study. Lancet. 2011;378(9786):140-6.

15. Heintz E, Wiréhn AB, Peebo BB, Rosenqvist U, Levin LA. Prevalence and healthcare costs of diabetic retinopathy: a population-based register study in Sweden. Diabetologia. 2010;53(10):2147-54.

16. Gerdtham UG, Clarke P, Hayes A, Gudbjornsdottir S. Estimating the cost of diabetes mellitus-related events from inpatient admissions in Sweden using administrative hospitalization data. Pharmacoeconomics. 2009;27(1):81-90.

17. Ghatnekar O, Carlsson K. Kostnader för insjuknande i stroke år 2009-En incidensbaserad studie. Lund: Institutet för hälsooch sjukvårdsekonomi; 2012.

18. Ghatnekar O, Persson U, Willis M, Ödegaard K. Cost effectiveness of becaplermin in the treatment of diabetic foot ulcers in four European countries. Pharmacoeconomics. 2001;19(7):767-78.

19. KPP database. https://skl.se/ekonomijuridikstatistik/ statistik/kostnadperpatientkpp/kppdatabas.1079. html. Accessed 6 Dec 2016.

20. Utomlänsprislista sluten och öppen vård. 2016. https://www.sthlm-gotland.se/2016-2/. Accessed 6 Dec 2016.

21. Palmer JL, Goodall G, Nielsen S, et al. Cost-effectiveness of insulin aspart versus human soluble insulin in type 2 diabetes in four European countries: subgroup analyses from the PREDICTIVE study. Curr Med Res Opin. 2008;24(5):1417-28.

22. Geelhoed-Duijvestijn PH, Pedersen-Bjergaard U, Weitgasser R, Lahtela J, Jensen MM, Östenson CG. Effects of patient-reported non-severe hypoglycemia on healthcare resource use, work-time loss, and wellbeing in insulin-treated patients with diabetes in seven European countries. J Med Econ. 2013;16(12):1453-61.

23. Jönsson L, Bolinder B, Lundkvist J. Cost of hypoglycemia in patients with type 2 diabetes in Sweden. Value Health. 2006;9(3):193-8.

24. Södra Regionvårdsnämnden. https://www.skane.se/ templates/Page.aspx?id=228838. Accessed 6 Dec 2016.

25. NordDRG somatisk öppen vård 2014. https://66.7. 199.160/ sthlmgot/2014-3/. Accessed 6 Dec 2016.

26. Persson U, Willis M, Odegaard K. A case study of ex ante, value-based price and reimbursement decision-making: TLV and rimonabant in Sweden. Eur J Health Econ. 2010;11(2):195-203.

27. Goodall G, Jendle JH, Valentine WJ, et al. Biphasic insulin aspart 70/30 vs insulin glargine in insulin naive type 2 diabetes patients: modelling the longterm health economic implications in a Swedish setting. Int J Clin Pract. 2008;62(6):869-76.

28. Prompers L, Huijberts M, Schaper N, et al. Resource utilisation and costs associated with the treatment of diabetic foot ulcers-prospective data from the Eurodiale Study. Diabetologia. 2008;51(10):1826-34.

29. Pharmaceutical Benefits Board. General guidelines for economic evaluations from the Pharmaceutical Benefits Board (LFNAR 2003:2). https://www.tlv. se/Upload/English/Guidelines-for-economic-evalua tions-LFNAR-2003-2.pdf. Accessed 6 Dec 2016.

30. Mullins P, Sharplin P, Yki-Jarvinen H, Riddle MC, Haring HU. Negative binomial meta-regression analysis of combined glycosylated hemoglobin and hypoglycemia outcomes across eleven phase III and IV studies of insulin glargine compared with neutral protamine Hagedorn insulin in type 1 and type 2 diabetes mellitus. Clin Ther. 2007;29(8): 1607-19.

31. Kiadaliri AA, Gerdtham UG, Eliasson B, Carlsson KS. Cost-utility analysis of glucagon-like peptide- 1 agonists compared with dipeptidyl peptidase- 4 inhibitors or neutral protamine Hagedorn basal insulin as add-on to metformin in type 2 diabetes in Sweden. Diabetes Ther. 2014;5(2):591-607.

32. Nathan DM, Cleary PA, Backlund JY, Diabetes Control and Complications Trial/Epidemiology of Diabetes Interventions and Complications (DCCT/ EDIC) Study Research Group, et al. Intensive diabetes treatment and cardiovascular disease in patients with type 1 diabetes. $\mathrm{N}$ Engl J Med. $2005 ; 353(25): 2643-53$.

33. Diabetes Control Complications Trial (DCCT)/Epidemiology of Diabetes Interventions and Complications (EDIC) Study Research Group. Mortality in type 1 diabetes in the DCCT/EDIC versus the general population. Diabetes Care. 2016;39(8): 1378-83.

34. Huxley RR, Peters SA, Mishra GD, Woodward M. Risk of all-cause mortality and vascular events in women versus men with type 1 diabetes: a systematic review and meta-analysis. Lancet Diabetes Endocrinol. 2015;3(3):198-206.

35. Huxley R, Barzi F, Woodward M. Excess risk of fatal coronary heart disease associated with diabetes in men and women: meta-analysis of 37 prospective cohort studies. BMJ. 2006;332:73-8. 
36. Woodward M, Huxley RR. Increased risk of coronary heart disease in female smokers-authors reply. Lancet. 2012;379:803.

37. McEwan P, Foos V, Palmer JL, Lamotte M, Lloyd A, Grant D. Validation of the IMS CORE diabetes model. Value Health. 2014;17(6):714-24.

38. American Diabetes Association. 6. Glycemic Targets. Diabetes Care. 2017;40(Suppl 1):S48-56.

39. National Institute for Health and Care Excellence. Technology appraisal guidance TA151. Continuous subcutaneous insulin infusion for the treatment of diabetes mellitus. https://www.nice.org.uk/ guidance/ta151. Accessed 3 April 2017.
40. Pieber TR, Draeger E, Kristensen A, Grill V. Comparison of three multiple injection regimens for type 1 diabetes: morning plus dinner or bedtime administration of insulin detemir vs. morning plus bedtime NPH insulin. Diabet Med. 2005;22(7):850-7.

41. Dornhorst A, Lüddeke HJ, Honka M, Ackermann RW, Meriläinen M, Gallwitz B, Sreenan S, PREDICTIVE Study Group. Safety and efficacy of insulin detemir basal-bolus therapy in type 1 diabetes patients: 14-week data from the European cohort of the PREDICTIVE study. Curr Med Res Opin. 2008;24(2):369-76. 